\title{
Prevalence of toddler, child and adolescent overweight and obesity derived from primary care electronic medical records: an observational study
}

\author{
Suzanne Biro MPH, Dave Barber MD, Tyler Williamson PhD, Rachael Morkem MSc, \\ Shahriar Khan MSc, Ian Janssen PhD
}

\section{Abstract}

Background: Population monitoring and surveillance of objectively measured child weight data in Canada is limited to national surveys with poor regional applicability, and no healthy weight data are available for children less than 2 years of age. We aimed to determine the prevalence of childhood overweight and obesity using objective measures derived from primary care electronic medical records.

Methods: Observational data included all height and weight records for children less than 20 years of age, between 2004 and 2013 , from 3 Ontario primary care research networks. We calculated body mass index (BMI)-for-age and weight-for-length using the World Health Organization Growth Standards and Reference to assign growth status indicator categories by age group. Descriptive data and prevalence estimates were generated for 2013. We also compared weight-for-length for children less than 2 years of age with a corresponding billing code for known well-child visits.

Results: Our study included 8261 children with a corresponding growth status indicator, a sample close to 4 times larger than the national survey sample. In 2013, $28.4 \%$ of children aged $5-19$ years, and $6 \%$ of children aged $0-5$ years, were categorized as overweight or obese. Between 2008 and 2013, the total number of 18-month well baby visit billing codes was 1152; 6.9\% of this group were categorized as overweight or obese; $19.2 \%$ were categorized as having risk of overweight.

Interpretation: Primary care electronic medical records show good potential for ongoing population monitoring of overweight and obesity, particularly for very young children for whom early intervention is likely to show the greatest positive health impact.

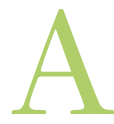

ccording to national survey data, one-third of Canadian children and adolescents aged 5 to 17 years are overweight or obese. ${ }^{1}$ Children with obesity have higher risk for both short-term health consequences ${ }^{2-5}$ and long-term persistence of obesity into adulthood. ${ }^{6-8}$ Evidence shows that early childhood is a critical time for obesity prevention strategies and that early markers of obesity could be targeted for universal and individual intervention strategies to show positive, long-term, health benefits. ${ }^{9-11}$ In Canada, child and adolescent population health monitoring is limited. There are a few national surveys, such as the Canadian Community Health Survey (CCHS) (ages $\geq 12 \mathrm{yr}$ ), the Health Behaviour in School-Aged Children Survey (ages 11-15 yr) and the National Longitudinal Study of Children and Youth that provide population-level surveillance data. ${ }^{12-14}$ In 2004 and 2005 the CCHS included representa- tive subsamples in which height and weight were measured. Measured heights and weights are also obtained as part of the Canadian Health Measures Survey (CHMS) (aged 3-79 yr). ${ }^{15}$ However, data on 3-5 year olds represents about 500 children from across Canada. The absence of data for children less than 3 years of age is a critical gap, given that early

Competing interests: Suzanne Biro, David Barber, Tyler Williamson, Rachael Morkem, and Shahriar Khan report receiving grants from the Public Health Agency of Canada during the conduct of this study.

This article has been peer reviewed.

Correspondence to: Suzanne Biro, suzanne.biro@kflapublichealth.ca CMAJ Open 2016. DOI:10.9778/cmajo.20150108 
life trajectories in growth and development are of great importance in determining lifelong health and well-being. In addition, the lack of objectively measured data at regional levels severely limits design and evaluation efforts of a "whole system" public health approach to the prevention of childhood obesity. ${ }^{16}$

We conducted this study to determine the prevalence of overweight and obesity, using measured heights and weights for toddlers, children and adolescents aged less than 20 years, derived from a sample of primary care electronic medical records (EMRs) from the Canadian Primary Care Sentinel Surveillance Network (CPCSSN) chronic disease database. ${ }^{17,18}$ In particular, to fill the known data gap, we examined height and weight data for toddlers less than 2 years of age and assessed them in relation to a known well-child visit, the enhanced 18-month well-baby visit.

\section{Methods}

\section{Setting and sources of data}

The CPCSSN database contains standardized, deidentified EMR data, from multiple EMR platforms, from 10 primary care practice-based research networks across Canada. For this study, data were extracted from EMRs on all patients from 3 Ontario networks of the CPCSSN (the Eastern Ontario Network, the University of Toronto Practice Based Research Network and London's Deliver Primary Healthcare Information Project). Extracted data from EMRs included all patients who had an encounter with a CPCSSN primary care provider before Mar. 31, 2014. Duplicate patient records were removed, and remaining EMR data were standardized using established CPCSSN algorithmic coding processes. For example, each height and weight value was cleaned and converted into standard units (kilograms, centimetres). Following standardization, the EMR data were uploaded into the CPCSSN database. For this study, additional eligible patients were excluded if key measurement variables were missing: height (length), weight, date of height taken, date of weight taken, year of birth and month of birth.

Data for this observational study included all height and weight records for children under 20 years of age, between Jan. 1, 2004 and Dec. 31, 2013, to produce a sample for crosssectional research. Data from 2013 were selected to report growth status indicators because this year provided the largest sample set. In addition, we obtained the encounter date (clinic visit date), the child's month and year of birth, and the child's sex. The A002 and A002A fee codes corresponding to the enhanced 18 -month well-baby visit were also extracted. ${ }^{19}$ Because a toddler's primary care clinic encounter could be associated with either a wellness or illness visit, the fee code was used to assess weight classification against a known "well toddler" visit. To provide a larger data set for this comparison, toddler visits with length and height measurements collected on the same date were taken from Jan. 1, 2008, to Dec. 31,2013 . If a toddler had weight-for-length values available, the latest one was used.

\section{Measures}

The World Health Organization (WHO) Growth Standards (birth to age $5 \mathrm{yr}$ ) and Reference (ages 5-19 yr) were used to assign growth status indicators. ${ }^{20,21}$ Body mass index (BMI) was calculated from height and weight measurements that were collected on the same date for children and adolescents aged 5-19 years. If a child or adolescent had multiple BMI values available in 2013, the latest one was used. BMI-for-age was used as the growth status indicator, classified into 4 categories: "wasting," "normal weight," "overweight" and "obesity." The BMI-for-age cut-off point for "overweight" was greater than the 85th percentile and the cut-off point for "obesity" was greater than the 97 th percentile for these age groups.

As per recommendations outlined in the Canadian collaborative statement, using the new $\mathrm{WHO}$ growth charts, weightfor-length was used as the growth status indicator for children from birth to 2 years of age (toddlers). ${ }^{21}$ Weight-for-length was calculated from length and weight measurements that were collected on the same date. If a toddler had multiple weight-for-length values available between 2008 and 2013, the latest one was used. Similarly, for preschool-aged children (2-5 yr), BMI-for-age was used as the growth status indicator. Toddler and preschool-aged children were classified into 5 growth status indicator categories as "wasting," "normal weight," "risk of overweight," "overweight" and "obesity." The cut-off point for these age groups differ from older children and adolescents: the cut-off point for "risk of overweight" was greater than the 85th percentile, the cut-off point for "overweight" was greater than the 97th percentile, and the cut-off point for "obesity" was greater than the 99th percentile.

\section{Statistical analysis}

We calculated prevalence estimates for growth indicator variables and expressed the results in terms of percentage and corresponding $95 \%$ confidence intervals (CIs) by sex and age (as of the date for height or length and weight measurement). In addition, we compared the proportion of toddlers with the 18-month enhanced well-baby visit fee code to those without a fee code. Significant differences between prevalence estimates within variable categories were assessed using $\chi^{2}$ tests. Alpha was set a priori at 0.05 . Variable classifications and all statistical analyses were performed in 2015 using SAS, version 9.3 (SAS Institute, Cary, NC).

\section{Ethics approval}

This study was approved by the Health Sciences Research Ethics Board at Queen's University.

\section{Results}

In total, 349613 patient records were extracted from source EMRs. Duplicate records (5915) were identified and removed, and the remaining 343698 records were uploaded to the CPCSSN database. Patient records with a missing month of birth (118 139), a missing or invalid height or weight measurement or weight measurement without a height measurement taken on the same date (100 986) were excluded. Records for 
patients aged 20 years and older were removed from the data set (97 070). A further 4651 weight and height records in the remaining data set were removed because the measurements were taken outside of the study period. The final child and adolescent sample of children with weight and height records (with the same measurement date) taken between Jan. 1, 2008, and Dec. 31, 2013, was 22 852. See Figure 1 for a flow diagram of the study sample inclusion process.
In 2013, there was a total of 5310 school-aged children, aged 5-19 years, with BMI-for-age calculated from height and weight measurements that were collected on the same date. There was a total of 1842 preschool-aged children, 2-5 years of age, with BMI-for-age and a total of 1127 toddlers (aged 0-2 yr) with a weight-for-length calculated from length and weight measurements that were collected on the same date in 2013. This represents a total of 8279 children, from birth to

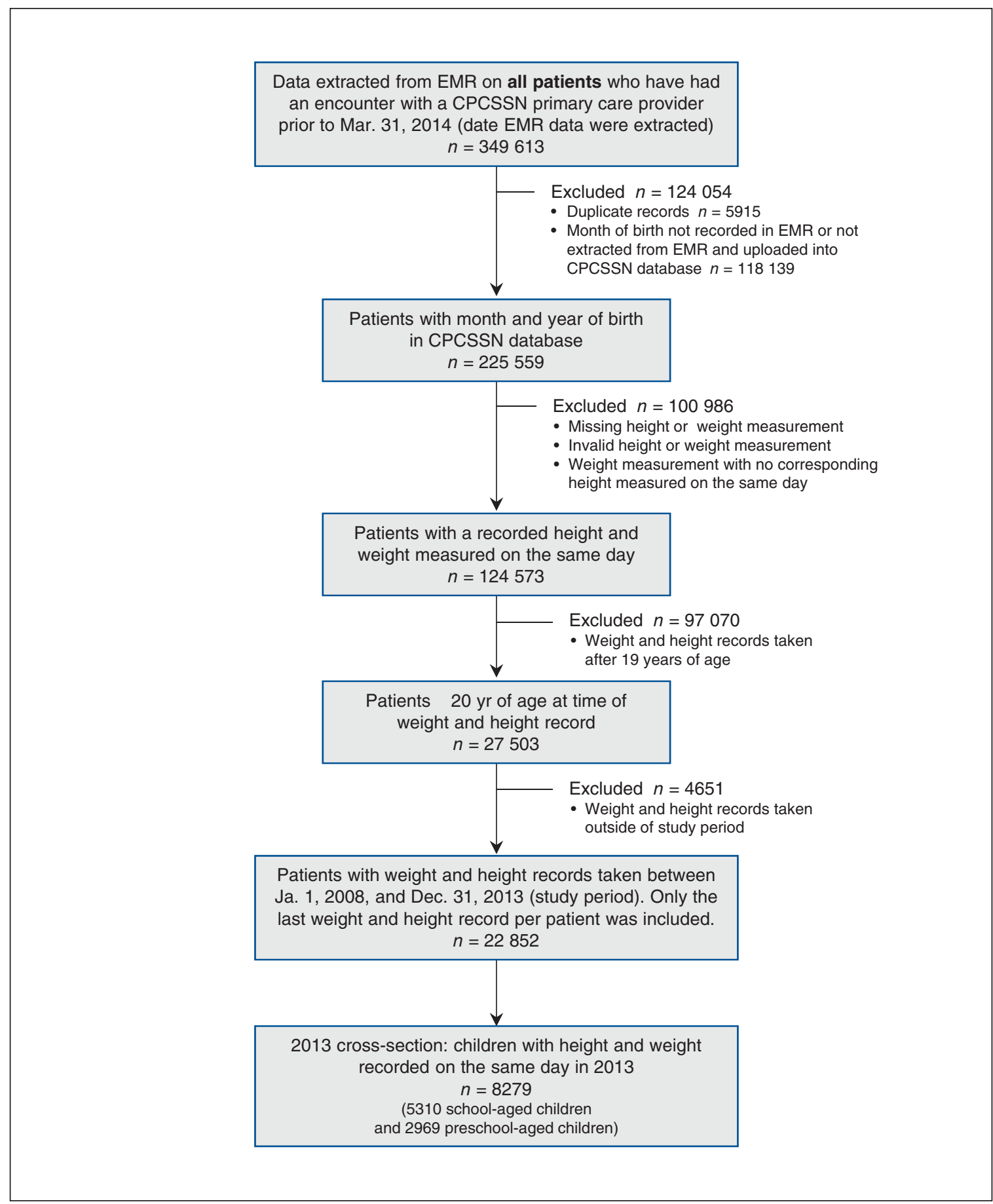

Figure 1: Selection of study sample. CPCSSN = Canadian Primary Care Sentinel Surveillance Network, EMR = electronic medical record. 
19 years of age, with a growth status indicator derived from objectively measured height (length) and weight.

BMI-for-age for school-aged children (aged 5-19 yr) derived from the last height and weight measurements taken from encounters in 2013 are presented in Table 1. The overall prevalence of overweight and obesity was $28.4 \%$. Boys and girls were equally represented $(48.1 \%$ and $51.8 \%$, respectively). Significantly more boys aged $12-19$ years were classified as overweight and obese compared with girls in the same age group. For boys 5-11 years of age, significantly more were classified as obese compared with girls in the same age group. It follows that girls were significantly more likely to be classified as normal weight compared with boys. There were no significant differences across age groups within BMI-forage categories for children and adolescents aged 5-19 years.

The percentage distribution of toddler (aged 0-2 yr) and preschool children (aged 2-5 yr) by growth status indicator, weight-for-length and BMI-for-age are presented in Table 2. Overall, $6.0 \%$ of toddlers and preschool-aged children were classified as overweight or obese in $2013 ; 18.1 \%$ were classified as having risk of overweight. Although we recognize that different growth indicators for these 2 age groups may prohibit comparison of growth between age groups, there appeared to be significantly more toddlers classified as wasting (6.8\%) compared with preschool-aged children (2.7\%) (and consequently, preschool-aged children were more likely to be classified as having normal weight). Both toddler and preschool-aged girls were significantly more likely to be classified as normal weight compared with boys in the same age groups.

Between 2008 and 2013, toddlers who had physician encounters without an 18-month enhanced well-baby visit fee code assigned were significantly more likely to be classified as wasting compared with toddlers with well-baby visits $(9.1 \% \mathrm{v}$.
$3.3 \%$, respectively) (Table 3 ). Significantly more boys than girls in the wasting category $(10.9 \%$ v. $7.1 \%$, respectively) visited their physician for reasons other than a well-baby visit. The overall percentage of toddlers who were classified as overweight and obese between 2008 and 2013 was $6.7 \%$; $17.5 \%$ were classified as having risk of overweight.

\section{Interpretation}

Our results suggest that $6.7 \%$ of toddlers aged less than 2 years are already overweight or obese and that $18.0 \%$ of toddlers are at risk of overweight. For school-aged children and adolescents (aged 5-19 yr), population estimates of overweight and obesity in our study are slightly lower than estimates derived from the CHMS (2009 to 2011) for children aged 5-17 years $^{22}$ (28.4\% v. 31.5\%, respectively). This lower estimate is likely due to more "unwell" child visits with primary care providers in our study population compared with a general population. Similarities across weight-for-length classifications for normal, risk of overweight, overweight and obesity for toddlers less than 2 years of age with and without a "well-child visit" code suggest that weight-for-length measures derived from primary care EMRs can provide good proxy population risk of overweight, overweight and obesity estimates for this younger age group. The discrepancy between groups for the wasting category supports the inherent population bias in our study: it is likely that children with poor weight gain during infancy or who are unwell at a younger age visit primary care providers more often.

Our study includes height (length) and weight measurements for a large number of children and adolescents less than 20 years of age and population assessment measures for toddlers and preschool-aged children less than 3 years of age.

Table 1: Percentage distribution of school-aged children and adolescents, by BMI-for-age category in 2013

\begin{tabular}{|c|c|c|c|c|c|}
\hline \multirow[b]{2}{*}{ Age group, yr } & \multirow[b]{2}{*}{ No. of children } & \multicolumn{4}{|c|}{ Percentage $(95 \% \mathrm{Cl})$} \\
\hline & & Wasting & Normal weight & Overweight* & Obesity† \\
\hline \multicolumn{6}{|c|}{ All children and adolescents } \\
\hline $5-11$ & 2649 & 2.6 (1.9 to 3.2 ) & 69.5 (67.7 to 71.2$)$ & 18.1 (16.6 to 19.6$)$ & 9.9 (8.7 to 11.0$)$ \\
\hline $12-19$ & 2661 & 1.5 (1.1 to 2.0$)$ & 69.6 (67.8 to 71.4$)$ & $18.0(16.5$ to 19.5$)$ & $10.9(9.7$ to 12.1$)$ \\
\hline $5-19$ & 5310 & 2.1 (1.7 to 2.4$)$ & 69.5 (68.3 to 70.8$)$ & $18.0(17.0$ to 19.1$)$ & 10.4 (9.5 to 11.2$)$ \\
\hline \multicolumn{6}{|l|}{ Boys } \\
\hline $5-11$ & 1356 & 3.3 (2.3 to 4.3 ) & 65.7 (63.1 to 68.3$)$ & 19.4 (17.3 to 21.5$)$ & 11.6 (9.8 to 13.3$)$ \\
\hline $12-19$ & 1201 & $1.8(1.0$ to 2.6$)$ & 64.2 (61.4 to 66.9$)$ & 20.8 (18.5 to 23.2$)$ & $13.2(11.2$ to 15.1$)$ \\
\hline $5-19$ & 2557 & 2.6 (2.0 to 3.3 ) & 65.0 (63.1 to 66.9$)$ & 20.1 (18.5 to 21.6$)$ & $12.3(11.0$ to 13.6$)$ \\
\hline \multicolumn{6}{|l|}{ Girls } \\
\hline $5-11$ & 1293 & $1.8(1.0$ to 2.5$)$ & $73.4 \ddagger(70.9$ to 75.8$)$ & 16.7 (14.6 to 18.8$)$ & $8.1 \ddagger(6.6$ to 9.6$)$ \\
\hline $12-19$ & 1460 & $1.3(0.7$ to 1.9$)$ & $74.0 \ddagger(71.8$ to 76.3$)$ & $15.7 \ddagger(13.8$ to 17.6$)$ & $9.0 \ddagger(7.5$ to 10.5$)$ \\
\hline $5-19$ & 2753 & 1.5 (1.0 to 2.0$)$ & $73.7 \ddagger(72.1$ to 75.4$)$ & $16.2 \ddagger(14.8$ to 17.6$)$ & $8.6 \ddagger(7.5$ to 9.6$)$ \\
\hline $\begin{array}{l}\text { Note: BMI = Body } \\
{ }^{*} \text { Cut-off }>85 \text { th pe } \\
\text { †Cut-off }>97 \text { th pe } \\
\text { †Significantly diffe }\end{array}$ & $\begin{array}{l}\text { ex, } \mathrm{Cl}=\text { confidence } \\
\text { boys within the sam }\end{array}$ & roup $(p<0.05)$. & & & \\
\hline
\end{tabular}




\section{OPEN}

Research

Our study sample was almost 4 times larger than the national survey sample from the second cycle of the CHMS. ${ }^{22}$ Moreover, indicator variables were derived from objectively mea- sured length, height and weight records in a clinical setting. Parent-reported measures of child heights and weights are consistently underestimated. ${ }^{23}$ It is commonly agreed that the

Table 2: Percentage distribution of toddler and preschool-aged children, by growth status indicator* category in 2013

\begin{tabular}{|c|c|c|c|c|c|c|}
\hline \multirow{2}{*}{$\begin{array}{l}\text { Age } \\
\text { group, yr }\end{array}$} & \multirow{2}{*}{$\begin{array}{l}\text { No. of } \\
\text { children }\end{array}$} & \multicolumn{5}{|c|}{ Percentage $(95 \% \mathrm{Cl})$} \\
\hline & & Wasting & Normal weight & Risk of overweight† & Overweightł & Obesity§ \\
\hline \multicolumn{7}{|c|}{ All children } \\
\hline $0-2$ & 1127 & 6.8 (5.3 to 8.3 ) & 68.5 (65.7 to 71.3$)$ & 18.0 (15.7 to 20.3$)$ & 5.5 (4.1 to 6.9$)$ & $1.2(0.5$ to 1.8$)$ \\
\hline $2-5$ & 1842 & 2.7 (1.9 to 3.4$)$ ๆ & 73.5 (71.4 to 75.5$)$ व & 18.2 (16.4 to 20.0$)$ & 4.0 (3.0 to 4.9 ) & 1.7 (1.1 to 2.4$)$ \\
\hline $0-5$ & 2969 & 4.2 (3.5 to 5.0$)$ & 71.6 (69.9 to 73.2 ) & 18.1 (16.7 to 19.5$)$ & 4.5 (3.8 to 5.3 ) & 1.5 (1.1 to 2.0$)$ \\
\hline \multicolumn{7}{|l|}{ Boys } \\
\hline $0-2$ & 566 & 8.1 (5.8 to 10.5 ) & 63.8 (59.7 to 67.8 ) & 20.1 (16.7 to 23.5 ) & 6.7 (4.6 to 8.9 ) & 1.2 (0.2 to 2.2$)$ \\
\hline $2-5$ & 918 & 3.7 (2.4 to 5.0$)$ & 70.2 (67.1 to 73.2$)$ & 19.5 (16.9 to 22.1$)$ & 4.4 (3.0 to 5.7 ) & 2.3 (1.3 to 3.3 ) \\
\hline $0-5$ & 1484 & $5.4(4.2$ to 6.6$)$ & 67.7 (65.3 to 70.1$)$ & 19.7 (17.7 to 21.8$)$ & $5.3(4.1$ to 6.4$)$ & 1.9 (1.2 to 2.6$)$ \\
\hline \multicolumn{7}{|l|}{ Girls } \\
\hline $0-2$ & 561 & 5.5 (3.5 to 7.5$)$ & $73.3(69.5 \text { to } 77.0)^{\star *}$ & 15.9 (12.8 to 19.0$)$ & 4.3 (2.5 to 6.0$)$ & 1.1 (0.1 to 2.0$)$ \\
\hline $2-5$ & 924 & $1.6(0.8$ to 2.5$)$ & $76.7(74.0 \text { to } 79.5)^{\star \star}$ & $16.9(14.4$ to 19.4$)$ & 3.6 (2.3 to 4.8 ) & $1.2(0.4$ to 1.9$)$ \\
\hline $0-5$ & 1485 & $3.1(2.2 \text { to } 4.0)^{\star \star}$ & $75.4(73.2 \text { to } 77.6)^{\star *}$ & 16.5 (14.6 to 18.4$)$ & 3.8 (2.8 to 4.8$)$ & $1.1(0.6$ to 1.7$)$ \\
\hline
\end{tabular}

Note: $\mathrm{Cl}=$ confidence interval.

${ }^{*}$ For children birth to 2 years of age, weight-for-length was used as the growth status indicator; for children 2 to 5 years of age, BMI-for-age was used as the growth status

indicator. Cut-off points are the same for each indicator.

†Cut-off $>85$ th percentile.

$\ddagger$ Cut-off $>97$ th percentile.

§Cut-off $>$ 99.9th percentile.

१Significantly different from toddlers $(p<0.05)$.

${ }^{*}$ Significantly different from boys within the same age group $(p<0.05)$.

Table 3: Percentage distribution of toddlers less than 2 years of age, by weight-for-length category, with and without the 18-month enhanced well baby visit fee code (2008-2013)

\begin{tabular}{|c|c|c|c|c|c|c|}
\hline \multirow[b]{2}{*}{ Group } & \multirow[b]{2}{*}{$\begin{array}{l}\text { No. of } \\
\text { children }\end{array}$} & \multicolumn{5}{|c|}{ Percentage $(95 \% \mathrm{Cl})$} \\
\hline & & Wasting & Normal weight & $\begin{array}{c}\text { Risk of } \\
\text { overweight }^{\star}\end{array}$ & Overweight† & Obesity \\
\hline \multicolumn{7}{|l|}{ All toddlers } \\
\hline 18-month fee code & 1154 & 3.3 (2.2 to 4.4$)$ & 70.6 (68.0 to 73.3 ) & 19.2 (16.9 to 21.6$)$ & 6.1 (4.6 to 7.5$)$ & $0.8(0.2$ to 1.3$)$ \\
\hline Without fee code & 2000 & 9.1 (7.8 to 10.3$) \S$ & 68.1 (66.0 to 70.2 ) & 16.5 (14.8 to 18.2$)$ & 5.3 (4.3 to 6.3 ) & $1.1(0.6$ to 1.5$)$ \\
\hline All aged $<2 \mathrm{yr}$ & 3154 & $6.9(6.0$ to 7.8$)$ & 69.0 (67.4 to 70.7) & 17.5 (16.2 to 18.8$)$ & 5.6 (4.8 to 6.4$)$ & $1.0(0.6$ to 1.3$)$ \\
\hline \multicolumn{7}{|l|}{ Boys } \\
\hline 18-month fee code & 560 & $3.8(2.1$ to 5.4$)$ & 68.2 (64.3 to 72.2$)$ & 20.9 (17.4 to 24.3 ) & 6.1 (4.0 to 8.1$)$ & $1.1(0.1$ to 2.0$)$ \\
\hline Without fee code & 1032 & 10.9 (8.9 to 12.8$)$ & 65.9 (63.0 to 68.8$)$ & $16.7(14.3$ to 19.0$)$ & 5.7 (4.3 to 7.2$)$ & $0.9(0.3$ to 1.5$)$ \\
\hline All boys aged $<2 \mathrm{yr}$ & 1592 & 8.4 (7.0 to 9.7$)$ & $66.7(64.4$ to 69.1$)$ & $18.2(16.2$ to 20.1$)$ & 5.8 (4.7 to 7.0$)$ & $0.9(0.4$ to 1.4$)$ \\
\hline \multicolumn{7}{|l|}{ Girls } \\
\hline 18-month fee code & 594 & 2.9 (1.4 to 4.3$)$ & $72.9(69.2$ to 76.6$)$ & 17.7 (14.5 to 20.8$)$ & 6.1 (4.1 to 8.1$)$ & $0.5(-0.1$ to 1.2$)$ \\
\hline Without fee code & 968 & 7.1 (5.5 to 8.8$)$ ) & 70.5 (67.5 to 73.4$)$ & $16.3(13.9$ to 18.7$)$ & 4.9 (3.4 to 6.3$)$ & $1.2(0.5$ to 2.0$)$ \\
\hline All girls aged $<2 \mathrm{yr}$ & 1562 & 5.5 (4.3 to 6.7$)$ & 71.4 (69.1 to 73.7$)$ & 16.8 (14.9 to 18.7$)$ & 5.3 (4.2 to 6.5$)$ & $1.0(0.4$ to 1.5$)$ \\
\hline \multicolumn{7}{|c|}{$\begin{array}{l}\text { Note: } \mathrm{Cl}=\text { confidence interval. } \\
{ }^{*} \text { Cut-off }>85 \text { th percentile. } \\
\text { †Cut-off > } \\
\text { †Cut-off percentile. } \\
\text { †C 99.9th percentile. } \\
\text { §Significantly different from toddlers with the } 18 \text {-month enhanced well baby visit code }(p<0.05) \text {. } \\
\text { ๆSignificantly different from boys within the same fee code category }(p<0.05) \text {. }\end{array}$} \\
\hline
\end{tabular}


best place for measuring length, height and weight is in primary care settings during routine wellness visits; this setting minimizes concerns about unintended negative consequences related to growth monitoring in other settings (e.g., schools) such as stigmatization; it ensures appropriate equipment is used; it provides ongoing staff training; and it follows measurement protocols..$^{24-26}$

\section{Limitations}

Our results depend on the quality of data that we were able to extract. The recording of primary care EMR data continues to suffer entry error and can be absent or unavailable for use. ${ }^{27-29}$ Missing measurements for length, height and weight and data standardization are variable across clinics and EMRs, as well as within the same EMR..$^{30,31}$

Our study population was limited to patients who visit their primary care providers. In a study investigating the representativeness of patients in CPCSSN, network patients were reasonably representative of patients in Canadian primary care practices and only somewhat representative of the Canadian general population. ${ }^{32}$ Ontario had the highest proportion of patients in CPCSSN; provincial-level comparison was reasonable. ${ }^{32}$

Our data were derived from records from physicians who participate as sentinels with the CPCSSN, limiting data extraction to include only providers who use EMRs. Although the number of primary care physicians using EMRs in Canada (77.6\%) has more than doubled since 2006, there may be practice differences between providers who use or do not use EMRs. ${ }^{33,34}$ Because our study population comprised toddlers, children and adolescents who visit their primary care provider, the children may represent a population with shifting growth indicator measures due to medical reasons, biasing our prevalence estimates. ${ }^{35}$

For toddlers less than 2 years of age, length is most often measured lying down as opposed to standing. There are inherent practical challenges to providing accurate measurement of length for infants and toddlers, despite standardized techniques and equipment. ${ }^{21}$ For example, it is difficult for toddlers to lie still and to capture a measurement with full extension of the legs. Similarly, height measurements for older children may be biased by measurement variability. Despite measures taken by trained care providers in primary care settings, it is possible that growth indicator classifications may not be accurately derived given the measurement difficulty.

Finally, it is important to note that weight-for-length and BMI-for-age growth indicators represent only some of many risk factors, ${ }^{9,11,36}$ and that any prevention or treatment strategy, whether targeted or universal, must clearly account for the complexity of factors that influence healthy growth and development.

\section{Conclusion}

Evidence clearly indicates the need to assess weight status in children and adolescents, particularly for toddlers and preschoolers less than 3 years of age. ${ }^{25}$ Our study shows that
EMR data are a valuable source for this information. These results provide a foundation upon which to build an ongoing, regionally specific, longitudinal monitoring system for population healthy weight status of Canadian toddlers, children and adolescents, especially toddlers, against which prevention measures may be designed, implemented and evaluated. Although primary care could become an improved source for healthy weight surveillance, a whole system population health approach to prevention is necessary. ${ }^{16,25,37}$ Our study shows the first steps toward improving our knowledge so that, collectively, clinical and community partners know how, when and where to focus and scale successful health promotion programming and policies.

\section{References}

1. Roberts K, Shields M, de Groh M, et al. Overweight and obesity in children and adolescents: results from the 2009 to 2011 Canadian Health Measures Survey. Ottawa: Statistics Canada; 2012. Available: www.statcan.gc.ca/pub/82-003 -x/2012003/article/11706-eng.pdf (accessed 2013 Oct. 18).

2. Reilly JJ, Methven E, McDowell ZC, et al. Health consequences of obesity. Arch Dis Child 2003;88:748-52.

3. Freedman DS, Mei Z, Srinivasan SR, et al. Cardiovascular risk factors and excess adiposity among overweight children and adolescents : trhe Bogalusa Heart Study. 7 Pediatr 2007;150:12-17.e2.

4. Thompson DR, Obarzanek E, Franko DL, et al. Childhood overweight and cardiovascular disease risk factors: The national heart, lung, and blood institute growth and health study. 7 Pediatr 2007;150:18-25.

5. Skinner AC, Mayer ML, Flower K, et al. Using BMI to determine cardiovascular risk in childhood: how do the BMI cutoffs fare? Pediatrics 2009; 124:e905-12.

6. Park MH, Falconer C, Viner RM, et al. The impact of childhood obesity on morbidity and mortality in adulthood: a systematic review. Obes Rev 2012; 13:985-1000.

7. Singh AS, Mulder C, Twisk JW, et al. Tracking of childhood overweight into adulthood: a systematic review of the literature. Obes Rev 2008;9:474-88.

8. Herman KM, Craig CL, Gauvin L, et al. Tracking of obesity and physical activity from childhood to adulthood: the Physical Activity Longitudinal Study. Int 7 Pediatr Obes 2009;4:281-8.

9. Brisbois TD, Farmer AP, McCargar LJ. Early markers of adult obesity: a review. Obes Rev 2012;13:347-67.

10. Matusik P, Malecka-Tendera E. Overweight prevention strategies in preschool children. Int 7 Pediatr Obes 2011;6(Suppl 2):2-5.

11. Weng SF, Redsell SA, Swift JA, et al. Systematic review and meta-analyses of risk factors for childhood overweight identifiable during infancy. Arch Dis Child 2012;97:1019-26.

12. Canadian Community Health Survey - Annual component (CCHS). Ottawa: Statistics Canada. Available: www23.statcan.gc.ca/imdb/p2SV. pl? Function=getSurvey\&SDDS=3226 (accessed 2015 Oct. 6).

13. Roberts C, Freeman J, Samdal O, et al. The Health Behaviour in Schoolaged Children (HBSC) study: methodological developments and current tensions. Int 7 Public Health 2009;54(Suppl 2):140-50.

14. National Longitudinal Survey of Children and Youth (NLSCY). Ottawa: Statistics Canada. Available: www23.statcan.gc.ca/imdb/p2SV. pl?Function=getSurvey\&SDDS=4450 (accessed 2015 May 22).

15. Canadian Health Measures Survey (CHMS). Ottawa: Statistics Canada. Available: www23.statcan.gc.ca/imdb/p2SV.pl? Function=getSurvey\&SDDS= 5071\&Item_Id=129548\&lang=en (accessed 2013 Oct. 21)

16. Dietz WH, Baur LA, Hall K, et al. Management of obesity: improvement of health-care training and systems for prevention and care. Lancet 2015; 385:2521-33.

17. Birtwhistle R, Williamson T. Primary care electronic medical records: a new data source for research in Canada. CMA7 2015;187:239-40.

18. Birtwhistle R, Keshavjee K, Lambert-Lanning A, et al. Building a panCanadian primary care sentinel surveillance network: initial development and moving forward. 7 Am Board Fam Med 2009;22:412-22.

19. Enhanced 18-month well baby visit, and foot care services. The Education and Prevention Committee Bulletin, vol 8, no 5, p. 25-7. Toronto: Ontario Medical Association; 2010. Available: https://www.oma.org/Resources/ Documents/0805EPC_Bulletin.pdf (accessed 2015 May 15).

20. The WHO Child Growth Standards. Geneva: World Health Organization: 2006. Available: www.who.int/childgrowth/en/ (accessed 2014 Oct. 16).

21. Promoting optimal monitoring of child growth in Canada: using the new WHO growth charts. Collaborative public policy statement. Toronto: Dietitians of Canada; Ottawa: Canadian Pediatric Society; 2010. Available: www.dietitians.ca/ downloadable-content/public/tcg-position-paper.aspx (accessed 2013 Oct. 6). 
22. Roberts KC, Shields M, de Groh M, et al. Overweight and obesity in children and adolescents: results from the 2009 to 2011 Canadian Health Measures Survey. Health Rep 2012;23:37-41.

23. Shields M, Connor Gorber S, Janssen I, et al. Obesity estimates for children based on parent-reported versus direct measures. Health Rep 2011;22:47-58.

24. Ontario Agency for Health Protection and Promotion (Public Health Ontario). Measuring the health of infants, children and youth for public health in Ontario: Indicators, gaps and recommendations for moving forward. Toronto: Queen's Printer for Ontario; 2013.

25. Canadian Task Force on Preventive Health Care. Recommendations for growth monitoring, and prevention and management of overweight and obesity in children and youth in primary care. CMA7 2015;187:411-21.

26. Himes JH. Challenges of accurately measuring and using BMI and other indicators of obesity in children. Pediatrics 2009;124(Suppl 1):S3-22.

27. Shephard E, Stapley S, Hamilton W. The use of electronic databases in primary care research. Fam Pract 2011;28:352-4.

28. Greiver M, Barnsley J, Glazier RH, et al. Measuring data reliability for preventive services in electronic medical records. BMC Health Serv Res 2012;12:116.

29. Coleman N, Halas G, Peeler W, et al. From patient care to research: a validation study examining the factors contributing to data quality in a primary care electronic medical record database. BMC Fam Pract 2015;16:11.

30. Rigobon $\mathrm{AV}$, Birtwhistle $\mathrm{R}$, Khan $\mathrm{S}$, et al. Adult obesity prevalence in primary care users: An exploration using Canadian primary care sentinel surveillance network (CPCSSN) data. Can 7 Public Health 2015;106:e283-9.

31. Dean BB, Lam J, Natoli JL, et al. Use of electronic medical records for health outcomes research: a literature review. Med Care Res Rev 2009;66:611-38.

32. Queenan JA, Williamson T, Khan S, et al. Representativeness of patients and providers in the Canadian Primary Care Sentinel Surveillance Network: a cross-sectional study. CMA7 Open 2016;4:E28-32.

33. Zelmer J, Hagens S. Advancing primary care use of electronic medical records in Canada. Health Reform Observer, vol. 2, issue 3. Toronto: Canada Health Infoway; 2014. Available: www.infoway-inforoute.ca/en/component/ edocman/2134-advancing-primary-care-use-of-electronic-medical-records-in -canada/view-document?Itemid=101 (accessed 2015 May 27).

34. 2013 Survey results. Mississauga: National Physician Survey; 2013. Available: http://nationalphysiciansurvey.ca/surveys/2013-survey/survey-results/ (accessed 2014 Mar. 14)

35. Maayan L, Correll CU. Weight gain and metabolic risks associated with antipsychotic medications in children and adolescents. 7 Child Adolesc Psychopharmacol 2011;21:517-35.
36. Wheeler JJ. Risk of obesity at 4 to 6 years of age among overweight or obese 18-month-olds: community-based cohort study. Can Fam Physician 2013;59: e202-8.

37. Lobstein T, Jackson-Leach R, Moodie ML, et al. Child and adolescent obesity: part of a bigger picture. Lancet 2015;385:2510-20.

Affiliations: KFL\&A Public Health - Chronic Disease and Injury Prevention Division (Biro), Kingston, Ont.; Centre for Studies in Primary Care (Barber, Morkem, Khan), Queen's University, Kingston, Ont.; Department of Community Health Sciences (Williamson), Cumming School of Medicine, University of Calgary, Calgary, Alta.; School of Kinesiology and Health Studies (Janssen), Queen's University, Kingston, Ont.

Contributors: Suzanne Biro, David Barber, Tyler Williamson and Rachael Morkem contributed substantially to the conception and design of this work. Ian Janssen provided content expertise. Shahriar Khan and Rachael Morkem completed the analysis. Suzanne Biro drafted the original version of the article. Suzanne Biro, David Barber, Tyler Williamson, Rachael Morkem and Ian Janssen contributed substantially to the interpretation of data and revised the manuscript critically for important intellectual content. All of the authors approved the final version to be published and agreed to act as guarantors of the work.

Acknowledgements: The authors thank the Canadian Primary Care Sentinel Surveillance Network (CPCSSN) and following Ontario regional networks: the DELPHI (Deliver Primary Healthcare Information) Project; the University of Toronto Practice Based Research Network (UTOPIAN); the Eastern Ontario Network (EON); and their respective sentinel physicians, for providing the data for this study. This research was supported by the Centre for Studies in Primary Care at Queen's University and the EON, 1 of 10 research networks of the CPCSSN.

Supplemental information: For reviewer comments and the original submission of this manuscript, please see www.cmajopen.ca/content $/ 4 / 3$ / E538/suppl/DC1 